\title{
Study on Application of Piano Duet in Piano Teaching
}

\author{
Nan Yan \\ College of music, Ningxia University, Ningxia Yinchuan, 750021, China
}

Keywords: Piano duet, Piano teaching, Application, Study

\begin{abstract}
On the basis of piano teaching, piano duet is developed, and it is also a modern new playing form. Playing forms of piano duet mainly include four-hands playing and two-pianos playing. Piano duet player must have a certain sense of cooperation and coordination, and it can be seen that, piano duet is a kind of playing form with high musical artistic value. Based on this, in the actual piano teaching, more music educators begin to pay attention to and focus on teaching of piano duet. This paper deeply discusses the practical application of piano duet in piano teaching, aimed to better improve the effectiveness of piano teaching.
\end{abstract}

\section{Introduction}

For whichever playing form for playing piano duet, we are able to use the appropriate optimization methods to make piano teaching content richer. Perfection and optimization of teaching methods, can not only improve the students' enthusiasm to learn music, but also enhance students' creative ability on music. On this basis, synergy between students can be gradually improved, and students are enabled to more deeply and fully comprehend the true meaning of music. And since the implementation of the new teaching reform, teaching effect of piano duet gradually comes out, and plays a key role in piano teaching. Therefore, we should actively apply piano duet in piano teaching process, thereby increasing the effect of piano teaching.

\section{Development process of piano duet}

Playing form of piano duet firstly arose in Europe. Verse song played by Carlton pipe organ and four hands has been taken as four-hands playing origin track ${ }^{[1]}$. The four-hands playing is developed based on three-hand playing. On the basis of the teaching demand and the difficulty of player controlling two layers of keyboards, four-hands playing form appears. In the development process of piano duet, Mozart is the most famous four-hands playing musicians, and he created four-hands sonata. And with the promotion of Mozart, piano duet was known and also recognized by more persons, breaking the original teaching purposes. While four-hands playing form rapidly developed, two-pianos music score came into being and was continuously published, which, to some extent, marks the further development of piano duet.

\section{Characteristics of piano duet}

Playing forms of piano duet usually include four-hands playing and two-pianos playing, and both forms require two persons to cooperate to complete musical works playing, so we can say piano duet has following three features:

First, in the process of playing music works, player needs to be responsible for a certain part, so it is necessary to ensure a strong collaboration between players, thus making better performance. However, in the audience's point of view, key indicators for the evaluation of piano duet performance effect is not only to ensure strong personal abilities of player, but also to ensure certain extent and standard of cooperation between two players, thus reach a certain standard, thus achieving perfect and coordinated piano performance ${ }^{[2]}$.

Second, in the long-term development process, playing form of piano duet provides certain platform for part performance of music composer, also promotes the further development of music. 
Players apply four hands simultaneously to the music playing, making the exchange between parts clearer. Further, when the music playing reaches to a climax, the actual shock effect is more obvious.

Third, playing form of piano duet combines various symphonies with other types of music, therefore, in terms of form it provides a larger performance space for other forms of musical works playing. Under normal circumstances, piano duet parts can make adaption of ballet, opera and symphony music in line with specific requirements.

\section{Teaching value of piano duet}

Improve students' musical comprehensive quality. Four-hands and two-pianos playing forms of piano duet can train and exercise a variety of skills, and it is a new way of teaching, mainly including cooperation, coordination, tone control ability, and so on.

Enhance the interest and initiative of students to learn piano. Compared with one-piano playing, four-hands and two-pianos playing forms of piano duet are far more vivid, with richer connotation, more expressive, to the greatest extend exploring the function of piano itself. If this form can be actively introduced in the piano classroom teaching, we can break through the restrictions of traditional piano teaching mode, while cab also actively introduce competition and cooperation teaching mechanism. The piano duet has high requirements for choosing co-players, so the actual playing is better; however, it needs effective communication and interaction between players. Comparison and competition between students can not only improve students' active initiative to learn piano, make their learning potential fully excavated, and enable them to establish strong self-confidence, at the same time, to some extent also reflect the timeliness of classroom and extracurricular piano training of students. On this basis, the diversified choices of piano playing tracks are another key reason for interest of students to learn piano improved. In particular, most of the piano duet works have exquisite melody and bright rhythm, easy to enable students to have great interest of learning.

Improve students' musical sense and performance ability. Piano duet, this musical art has a strong feature of collaboration, and focuses on cooperation training in music of co-players, and its specific requirement is players should have a high artistic accomplishment and aesthetic taste, but also rigorous attitude towards art. In the process of cooperative playing, players are required to complementary, thus achieving coherence between them. Under normal circumstances, musical works parts of piano duet are very clear, and it is easy between players to changeover between the accompaniment and melody part, thus providing a favorable opportunity for musical dialogue and imitated playing between two players, to some extent, improving the ability to play singing melody works of players with poor performance basis ${ }^{[3]}$. However, in the practical cooperative playing of piano works with more obvious sense of rhythm, players with poor basic ability can also accept another player's influence. The most obvious advantage of two-pianos playing form of piano duet is that it can effectively develop hearing ability and cooperative ability of players, making their own sense of rhythm enhanced, thereby enabling the performance ability of plays to get exercised. In the cooperative playing, it is not that players give up themselves, but integrate and coordinate with emotions and feelings of cooperator based on players conveying musical emotions they understand, to improve the expressiveness of the music itself, and make it richer .

Develop students' cooperation and coordination ability. Solo-piano playing form focuses on self-expression, so during learning piano playing, students always lack the ability of cooperation, communication and coordination, which leads to that piano learning is severely constrained. In higher-level international competitions, it has been found that our piano players have strong musical sense, technology and control ability, but when working with other players, but they seriously lack cooperation skills, and their practical experience is not enough. So, two-pianos playing of piano duet can cultivate students' ability of cooperation and coordination. 


\section{Specific application of piano duet in piano teaching}

Listen carefully and master techniques. Initially, the piano duet is only applied in music teaching. In the process of its slow development, it is gradually applied in the performance, and now, in piano teaching, piano duet also presents its important role and value. Piano duet has higher technical requirements, showing coherence and uniformity characteristics, touching keys consistently, and then completely showing the coordination between main playing and different parts. On this basis, teaching of piano duet is required to focus on pedal training. During pedal training, students can effectively avoid confusion of musical thinking, and develop their musical listening and recognition ability. Therefore, in piano teaching, we should arrange students to deeply study piano duet works to be studied, listen carefully, to master the musical works, and then combine with playing features, to better play piano duet works.

Develop students' ability of coordination and innovation by using hands and feet at the same time. Piano duet teaching does not have a long development history in China, but most of the music colleges and training institutions have summarized its characteristics, and widely applied it throughout the process of piano teaching. Thus, at the present stage, piano duet has become the compulsory course in music colleges. After perfection and innovation, piano duet makes students more active in piano learning, and effectively improves their ability of innovative thinking ${ }^{[4]}$. The application of piano duet in piano teaching greatly enhances students' coordination ability to use hands and feet, and promotes the improvement of their performance level. In the teaching process, make appropriate adjustment according to the characteristics of piano duet.

First, in piano teaching, students need to practice piano keys, but also to control the volume. At the same time, we should also improve students' feeling to touch the keys, thereby ensuring that they have a comprehensive and in-depth understanding on sound production of piano.

Second, most of textbooks used in piano teaching are adapted according to the symphony, so in the actual teaching process, we should imitate the music so that students have a deeper understanding of different sounds and their changes, and thus improving their control ability on music.

Third, piano duet playing skills are important, but cannot be overemphasized, and are also required to fully embody the beauty of tone. Constant practice of piano duet musical works enables students to improve students' understanding on tone, harmony and tone control, rapidly enhances students' performance level. In addition, this approach can not only improve students' listening and recognition ability, at the same time, in the process of practice also enhance the level sense of parts during playing, making the connotation of music works richer.

Improve student' music accomplishment through piano duet teaching. Apply piano duet teaching in piano teaching, and take it as an important approach to train students' piano skills. This approach can not only improve students' piano skills, but also enhance students' coordination ability to use hands and feet, and cultivate their sense of collaboration. And these approaches are able to improve students' music accomplishment. On this basis, use four-hands and two-pianos playing forms of piano duet to make piano playing richer and more vivid and we can change the traditional mode of piano teaching. Mutual cooperation between players improves students' enthusiasm to learn piano, and both players promotes mutually and make progress together. Piano duet is always the approach to train musical skills of students, not only enabling students to have a deep understanding on piano playing skills, but also helping students improve their coordination and cooperation ability to effectively improve their piano music accomplishment. In piano duet teaching, whichever playing form, or whichever teaching method, can directly enhance the sense of competition between students, and greatly promote students' interest and imitative to learn piano. Make full use of diversified piano duet teaching practice, to ultimately meet diverse needs of piano teaching ${ }^{[5]}$.

Improve students' perception ability through piano duet teaching. It is not hard to understand piano duet playing techniques, and music teachers can reasonably arrange students to actually play parts during practice, which can help combine parts and melody, and plays an important role in training students' hearing ability of multi parts. At the same time, piano duet teaching method and traditional solo-piano teaching method are significantly different; however, musical skills are not difficult for understanding. Piano duet playing forms are more attractive, so after repeated practice, 
students can fully demonstrate the rhythm and intensity of playing music tracks. And, in teaching and practice, students are able to feel more deeply the overall beauty local beauty of piano playing track, which to some extent enhances students' perception ability in terms of music. In addition, piano duet requires collaboration and cooperation of several students for completing the play, so in the actual playing, students need to concentrate, and should ensure that all details of playing do not have any mistake. This requirement requires students to actively cultivate their observation ability and attention, and fully explore their logical thinking in music. After a long time of piano duet playing practice, students can improve their thinking and perception ability on music.

\section{Conclusions}

In summary, the deepening of education system reform leads the development of piano teaching. In actual piano teaching, in order to actively implement the thinking of piano education, and effectively enhance teaching efficiency, make piano educators begin to pay more attention to piano teaching methods and approaches. And active introduction of the piano duet in piano teaching, can not only improve students' overall quality, but also actively promote their overall development. Piano duet teaching makes piano learning more interesting and competitive, able to better develop students' interest in learning and playing piano. And in piano teaching, teachers should actively guide students to master methods and techniques of piano duet, and take advantage of the role and function of this teaching approach, thereby increasing students' interest in learning piano, to enhance the effect of piano learning.

\section{References}

[1] Wang Shuming Analysis on application of piano duet in piano teaching. Music Space, 2015 (3): 151-151.

[2] Dang Ling. On application of piano duet in piano teaching. Chifeng College Journal (Natural Science), 2014 (14): 237-239.

[3] Dang Ling. On application of piano duet in piano teaching. Chifeng College Journal (Natural Science), 2014 (9): 231-233.

[4] Wang Ke. On effective application of piano duet in piano teaching. Music Space, 2014 (1): 161-161.

[5] Wang Xiaomin. Study on application of piano duet in piano teaching. Music Panorama, 2014 (8): 153-153. 